\title{
Discussion on the Specifications and Needs of Fire Engines Procured by Miaoli County Fire Bureau
}

\author{
${ }^{1}$ Hung-Teng Chang, ${ }^{2}$ Cheng-I Hou, ${ }^{3}$ Ping-Chang Lin, ${ }^{*}$ Nick-Lin \\ 1,*Yu-Da University of Science and Technology, ${ }^{2,3}$ Chung Hua University \\ ${ }^{1}$ cht@ydu.edu.tw, ${ }^{2}$ cihou@chu.edu.tw, ${ }^{3}$ ballytour@gmail.com, ${ }^{*}$ nicklin911@yahoo.com.tw
}

\begin{abstract}
The annual average fire disaster in Taiwan was about 1,600 resulting and loss of about NTD 700 million. To this end, fire fighting organs have set up plans to enhance fire fighting and rescue capability. However, in terms of the procurement of equipment and fire engines, due to the confinement by the Government Procurement Law, narrow market, and cognition and differences of needs, they often fail to purchase a fire engine completely in line with the needs of firefighters, which affect the effectiveness of fire rescue.

To define the decision-making factors of specifications and needs of fire engines, this study proposed the factors based on relevant literature review and Modified Delphi Method, established decision-making hierarchical framework, and finally explored the weight of the factors through analytic hierarchy process (AHP).

It has been found that the influencing factors with degrees of importance in terms of the procurement of special fire engines are body and security of engines, accessory rescue equipment, and supplier conditions and built-in equipment. Besides, the brake, engine, chassis, and rigid structure of a fire engine are considered as important by firefighters and purchasing professionals. It can be seen that the most important factors are related to security, consistent, and continuous.
\end{abstract}

Keywords: firefighters, specifications and needs of fire engines, purchasing firefighting equipment

\section{INTRODUCTION}

Fire prevention, disaster rescue, and first aid are significant tasks for firefighters (Fire Control Law, 2011). In the face of disaster rescue work, firefighters must have disaster relief equipment with high quality, and conformance to requirements so as to keep security, improve efficiency, and reduce loss. However, due to the confinement of the Government Procurement Law (Chen, 2001), collusion among manufacturers and agents of fire engines and relevant equipment ( $\mathrm{Tu}$, Lin, Chen, and Huang, 2010), unworthy government officials, and non-governmental manufacturers (National Fire Agency, 2015), and top-down purchase concept (Chen, 2001), fire fighting organs fail to obtain appropriate rescue equipment in line with the needs of firefighters. Thus, this study aimed to adopt the questionnaires based on AHP and Modified Delphi Method to analyze the factors influencing the specification and needs so as to learn the specification and needs of the firefighters and offer the results as a reference for firefighting organs in terms of procurement of special fire engines. 


\section{Review of Literature on DelPhi Method, AHP, ANd SPecifications of Fire ENGINES}

Delphi Method provides experts with knowledge and experiences who may reach a consensus after full discussion and exchanges through specific programs, such as anonymity and written form and solve complex issues. This study employed Modified Delphi Method, collected literature and data of relevant issues, adopted anonymous group decision-making of experts without interference, and utilized statistical analysis and systematic data processing to integrate the opinions of experts in relevant fields so as to reach the consensus on the factors influencing the specifications and needs in terms of the purchase of fire engines.

AHP was used to identify the relative importance ratios and sort the order of elements through systematic problem decomposition and stratification of issues in terms of the factors influencing the specifications and needs in terms of the purchase of fire engines. The main steps include solving the decision-making issue, confirm research questions, select influencing factors, establishing hierarchical framework, design and implement questionnaire, establish pairwise comparison matrix, calculate max eigenvector and eigenvalue, verify consistency, calculate overall hierarchical weight, choose the best solutions and influencing factors of specifications and needs of fire engines, and reduce the risk of wrong decision. Therefore, this used AHP to analyze the elements.

According to literature, the factors influencing the purchase of fire engines can be roughly classified into four aspects: fire engine body and security, accessory rescue equipment, supplier conditions, appearance and built-in equipment, which are described as follows:

\subsection{Fire Engine Body and Security}

Fire engine security consists of two main parts: active and passive security. The former refers to "the ability of a vehicle to avoid collision", which is related to controllability and driving stability, while the latter depends on the vehicle structure and performance of interior restraint device (e.g., seat belt, airbag), wherein, vehicle structure is the most critical (Channel-Auto, 2015).

The main structure of a vehicle offers safe and comfortable space and correct assembly of engine, chassis, and parts (Wang, 2001). A moving vehicle shall face different environmental factors, such as topography, climate, and road conditions (Tsai, 2007). The selection of appropriate vehicle body structure and security is extremely important for the procurement of fire engines. This study included the two factors in the list of factors influencing the purchase of fire engines. The factors influencing vehicle body structure and security include brake, engine, chassis, and electronic security equipment.

\subsection{Accessory Rescue Equipment}

Accessory rescue outfit refer to the equipment can help firefighters to prevent and put out a fire and facilitate escape and rescue. According to the task requirements of fire engines, accessory rescue equipment contain essential elements, such as extra power unit, keep drivers and disaster site safe, and apply in a variety of disasters and accidents (Huang, 2009). The completeness of accessory rescue equipment (Ministry of the Interior, 2004) determines the effectiveness of firefighters in the 
face of emergent situations and the operation of complex equipment. Firefighters require firefighting equipment and equipment with good quality to face the challenges of disaster relief. Hence, this study included accessory rescue equipment in the list of factors influencing the purchase of fire engines. The factors influencing accessory rescue equipment include power take off (PTO), accessory rescue equipment, difficulty of operation, availability, and space planning of the equipment.

\subsection{Supplier Conditions}

The important factors about supplier conditions include vehicle brand, service quality, vehicle quality, maintenance, and performance capabilities. Kao, Ko, and Su (2015) deemed that higher service quality was, higher willingness to repurchase. Tseng and Hsieh (2012) pointed out that brand image was an important basis for consumers to choose goods. Feng and Chen (2015) asserted that product quality drove purchase willingness. Supplier condition was an important factor considered by fire fighting organs in terms of purchase of fire engines, including product quality, function, and design (Hsiao, 2012). The better the condition of suppliers of fire engines, the higher willingness of customer to purchase. Therefore, supplier condition was an indispensable factor to consider in the purchase of fire engines.

\subsection{Appearance and Built-In Equipment}

Li (2003) suggested that there were many factors affecting the purchase of a vehicle. Appearance could attract the attention of consumers affect their overall evaluation of a product and their willingness to purchase (Lai, Tung, and Huang, 2011). GPS (www.nani.com, 2015) could track the position of each fire engine and dispatch the one closest to a fire site to provide rescue. A driving recorder could offer dynamic data, mechanical condition, and safety of a vehicle (Cheng and Lin, 2004), which is particularly important for the purchase of a fire engine. Due to the requirements of missions, whiling riding a fire engine, firefighters need to wear complete equipment and simultaneously operate much complex equipment. Therefore, the front compartment is a factor attached with great importance. The above factors related to appearance and built-in equipment are sufficient to affect the purchase of a fire engine, which are the key points discussed in this study. The factors influencing appearance and built-in equipment include GPS, driving recorder, and double cabs of the front compartment.

\section{RESEARCH METHOD}

This study was designated to explore the weight of the decision-making factors influencing the specifications and needs of a fire engine used by firefighters and serve as a reference in the purchase of a fire engine. First, it collected the theories and researches related to the factors influencing the specifications and needs of a fire engine and preliminarily analyzed the factors. Through semi-open-ended questionnaire based on Modified Delphi Method to experts, it invited a total of 14 experts, including firefighters in Miaoli County and fire fighting experts with practical experiences. It summarized and evaluated the opinions of the experts to establish a decision-making hierarchical framework. Then, it implemented empirical researches based on AHP. The steps are described as follows: 


\section{Hung-Teng Chang et al.}

(1) Developing AHP questionnaire to explore the degrees of importance the factors influencing the specifications and needs of a fire engine.

(2) Collecting the questionnaire and conducting statistical analysis, including the pair comparison of the factors of a single level of the decision-making hierarchical framework and the factors of the aspects of specifications and needs of a fire engine.

(3) Establishing pair-comparison matrix.

(4) Calculating eigenvectors.

(5) Verifying consistency.

(6) Calculating the weight of overall assessment factors, understanding the rank of importance of each factor influencing the specifications and needs of a fire engine.

(7) Calculating the weighted value of the factors influencing the specifications and needs of a fire engine and understanding and understanding the preference of specifications and needs of a fire engine.

The flow chart of this study is shown below:

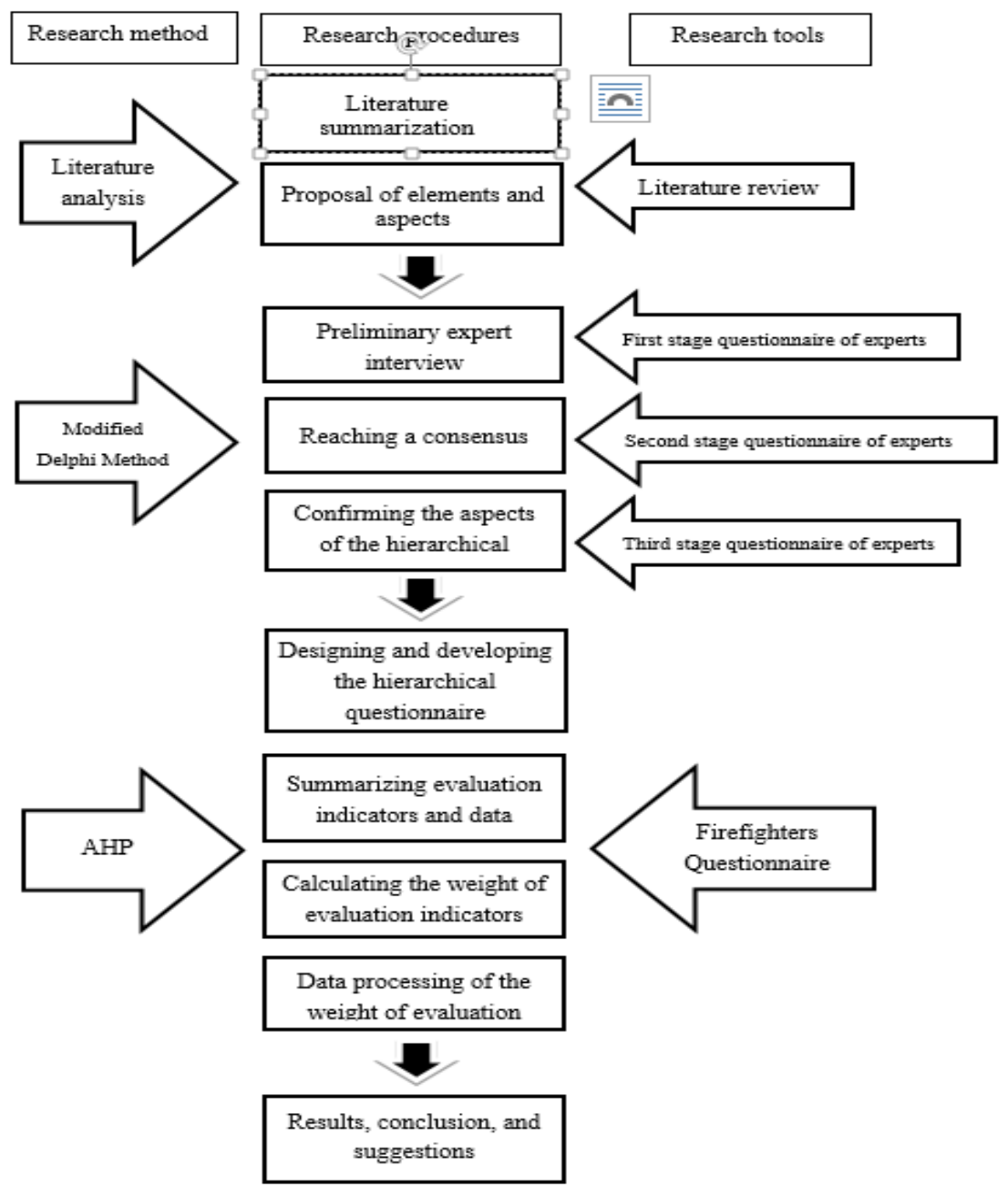

Figure1. The Flow Chart of this Study 
According to literature, the factors influencing the purchase of fire engines can be roughly classified into four aspects: namely, "fire engine body and security", "accessory rescue equipment", "supplier conditions", "appearance", and "built-in equipment. Fire engine body and security include brake, engine (horsepower/torsion), chassis (controllability), and electronic security equipment. Accessory rescue equipments include power take off (PTO), accessory rescue equipment, difficulty of operation, availability, and space planning of the equipment, and maintenance. Supplier conditions include service quality, maintenance, vehicle quality, availability, and performance capabilities. Built-in equipments include GPS, driving recorder, and double cabs of the front compartment.

Further, it used Modified Delphi Method to conduct a questionnaire to experts to preliminarily assess the appropriateness of the items. The response rate of the first round of questionnaire was $100 \%$. The first questionnaire result shows that the average values of "corporate image (evaluation)" and "vehicle appearance" are less than 3.5 while the standard deviations are greater than 1 . Thus, the two factors were deleted. The average values and standard deviations of other factors are in compliance with the selection criteria.

In addition, based on the open-ended questions in the first round of questionnaire, experts had provided valuable comments, aggregated as follows:

1. In the aspect of "supplier conditions", the concept of "corporate image (evaluation)" was general. It was about the perception of information related to companies of a consumer and not compliant with the theme of the specifications and needs of equipment of firefighters. After several discussions, the experts proposed to replace "corporate image (evaluation)" with "vehicle brand". In addition, since the usage rate of firefighting equipment by firefighters was high, while the maintenance of the equipment was professional and rely on the assistance of manufacturers, after discussion, the experts proposed two aspects related to "supplier conditions", that is, "maintenance capability" and "performance capability".

2. In the aspect of "appearance and built-in equipment", the concept of "vehicle appearance" was about the physiological resonance of a product by a consumer and not compliant with the theme of the specifications and needs of equipment of firefighters. Due to the requirements of missions, whiling riding a fire engine, firefighters need to wear complete equipment and simultaneously operate much complex equipment. Therefore, front compartment is a factor attached with great importance. After discussion, the experts proposed one aspect related to "appearance and built-in equipment", that is, "double cabs of the front compartment". 


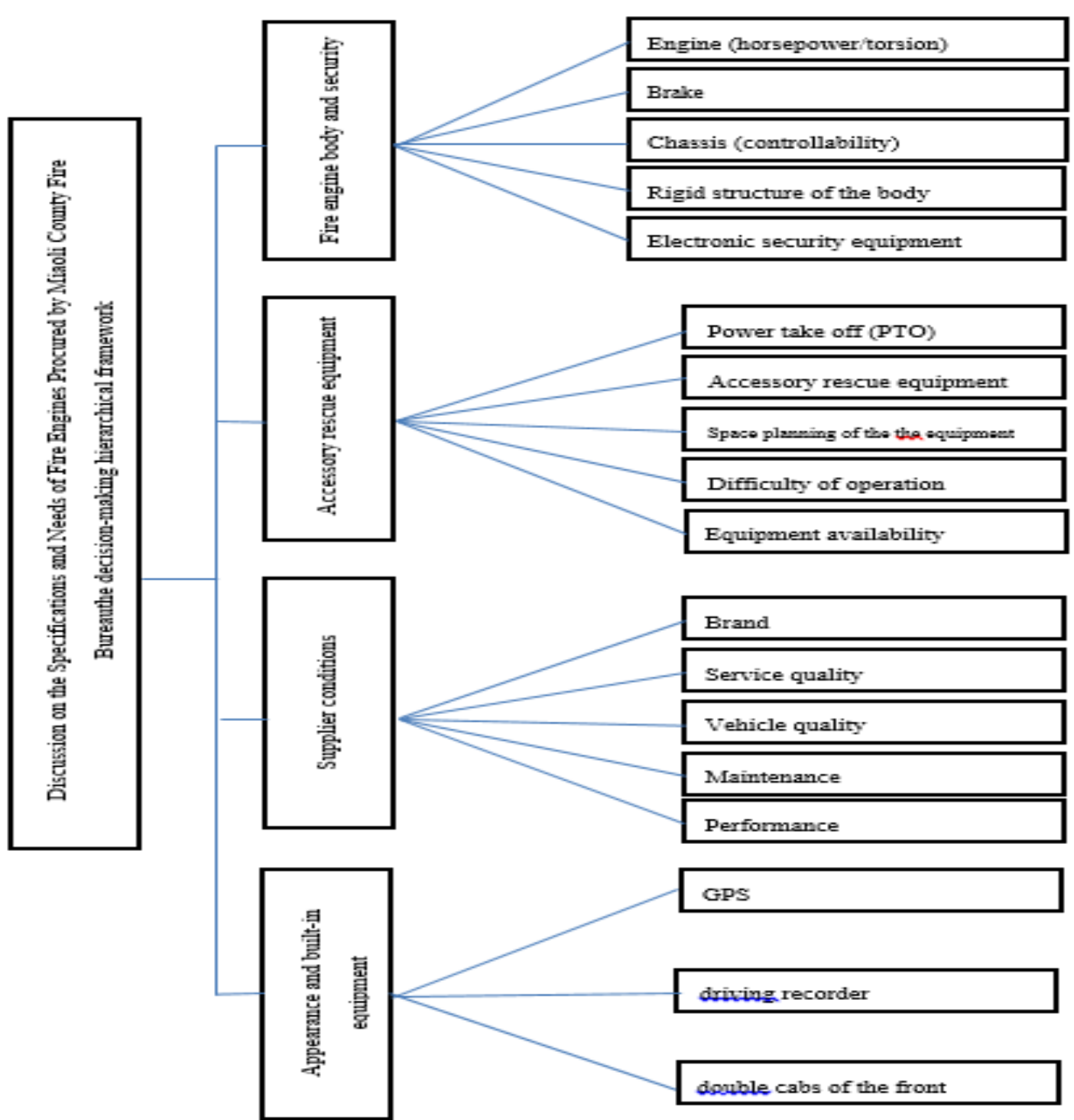

Figure2. Hierarchical Framework of the Discussion on the Specifications and Needs of Fire Engines Procured by Miaoli County Fire Bureau

In sum, "corporate image" in "supplier conditions" was replaced by "maintenance capability" and "performance capability", while "vehicle appearance" in "appearance and built-in equipment" by "double cabs of the front compartment". The newly added aspects were included in the second round of questionnaire. The response rate of the second round of questionnaire was 100\%. After support degree statistics, the newly added evaluation items were supported by other experts, thus they were accepted. Therefore, there were 18 factors influencing the purchase of a fire engine by Miaoli County Fire Bureau.

According to the needs of this study and referring to "typical AHP chart", this study developed the decision-making hierarchical framework shown as Figure 2.

The key points of the evaluation items are described in the following table: 
Discussion on the Specifications and Needs of Fire Engines Procured by Miaoli County Fire Bureau

Table1. Description of the Evaluation Items of the Factors Influencing the Purchase of a Fire Engine by Miaoli County Fire Bureau

\begin{tabular}{|c|c|c|}
\hline \multicolumn{2}{|c|}{ Evaluation Items } & Key points \\
\hline \multirow{5}{*}{ 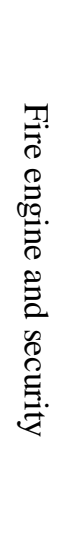 } & Brake & $\begin{array}{l}\text { Factors considered included reaction, average power, drainage, } \\
\text { structure, braking force, and frequency of replacement. }\end{array}$ \\
\hline & Engine(horsepower/torsion) & Fuel, ignition, cooling, lubricating and engine power. \\
\hline & Chassis(Controllability) & $\begin{array}{l}\text { Installation position, drive wheel configuration, driver's vision, } \\
\text { vehicle vibration, stability of direction, steering angle, vision, noise, } \\
\text { and cooling effect. }\end{array}$ \\
\hline & Rigid structure of the body & Safety, fuel consumption, comfort, center of gravity, and productivity. \\
\hline & $\begin{array}{l}\text { Electronic } \\
\text { equipment }\end{array}$ & $\begin{array}{l}\text { Controllability of wheel, stability of direction, braking distance, and } \\
\text { tire eccentric wear. }\end{array}$ \\
\hline
\end{tabular}

\begin{tabular}{|c|c|c|}
\hline \multicolumn{2}{|c|}{ Evaluation Items } & Key points \\
\hline \multirow{5}{*}{ 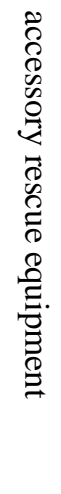 } & Power take off(PTO) & PTO. \\
\hline & Accessory rescue equipment & Consistency with the objectives and characteristics of tasks. \\
\hline & Difficulty of operation & $\begin{array}{l}\text { The consistency of the objectives and characteristics of functions of } \\
\text { equipment with the needs of firefighters. }\end{array}$ \\
\hline & Equipment availability & $\begin{array}{l}\text { The documents of authentication and certification and the } \\
\text { consistency actual start-up test results with the needs of firefighters. }\end{array}$ \\
\hline & $\begin{array}{l}\text { Space planning of the } \\
\text { equipment }\end{array}$ & $\begin{array}{l}\text { The consistency with the configuration guidelines of minimum } \\
\text { space occupied and maximum capacity and security design }\end{array}$ \\
\hline \multirow{5}{*}{ 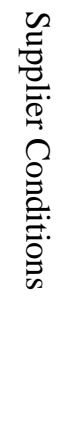 } & Brand & Corporate image, functional image, and product image. \\
\hline & Service quality & Reliability, tangibility, responsiveness, assurance, and empathy. \\
\hline & Vehicle quality & $\begin{array}{l}\text { Menu, features, reliability, consistency, durability, aesthetics, } \\
\text { service, and perceived quality. }\end{array}$ \\
\hline & Maintenance & $\begin{array}{l}\text { The maintenance capability of suppliers, latency time of materials } \\
\text { and parts, and warranty period. }\end{array}$ \\
\hline & Performance & Tangibility, responsiveness, assurance, and empathy \\
\hline
\end{tabular}

\begin{tabular}{|c|c|c|}
\hline \multicolumn{2}{|c|}{ Evaluation Items } & Key points \\
\hline \multirow{3}{*}{ 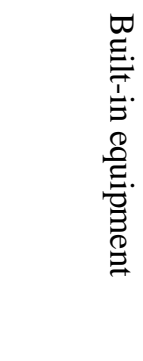 } & GPS & Usage period, coverage, accuracy, efficiency, and functionality. \\
\hline & Driving recorder & $\begin{array}{l}\text { Environmental adaptability, electricity demand, shock resistance } \\
\text { and crashworthiness, accuracy, memory, volume, and interface } \\
\text { expansion. }\end{array}$ \\
\hline & $\begin{array}{l}\text { Double cabs of the front } \\
\text { compartment }\end{array}$ & $\begin{array}{l}\text { Spatial comfort, seating comfort, ease of handling, and motion } \\
\text { trend design. }\end{array}$ \\
\hline
\end{tabular}




\section{RESULTS AND ANALYSIS}

According to a decision-making hierarchical framework, this study adopted AHP to develop hierarchical analysis questionnaires with firefighters in Miaoli County and fire fighting experts with practical experiences as its subjects and learned the factors influencing the specifications and needs of fire engines purchased by Miaoli County Fire Bureau. With purposive sampling, 14 people were selected, including 2 staffs of the organizer, 2 of the purchase unit, 3 of relevant departments, and 7 firefighters of the fire fighting organ.

This study used average values and standard deviations to reflect the opinions and degrees of importance and dispersion of the groups of experts on the aspects and questions of the "factors influencing the specifications and needs of fire engines purchased by Miaoli County Fire Bureau". Then, AHP was adopted to compare the factors within each level and confirm the weight vector of pairwise comparison matrix. With the compliance with requirements, it calculated relative weight of overall items evaluated and decided the priorities of the factors evaluated.

\subsection{Analysis on the Importance of the Factors Influencing the Purchase of a Fire Engine and Principal Criteria}

Table 3 shows the analysis of the importance of the factors influencing the purchase of a fire engine by Miaoli County Fire Bureau

Table3. Analysis on the Importance of the Factors Influencing the Purchase of a Fire Engine and Principal Criteria of Miaoli County Fire Bureau

\begin{tabular}{|l|l|l|l|l|l|l|}
\hline $\begin{array}{l}\text { Principal } \\
\text { Criteria }\end{array}$ & $\begin{array}{l}\text { Fire engine } \\
\text { body and } \\
\text { security }\end{array}$ & $\begin{array}{l}\text { accessory } \\
\text { rescue } \\
\text { equipment }\end{array}$ & $\begin{array}{l}\text { Supplier } \\
\text { conditions }\end{array}$ & $\begin{array}{l}\text { Built-in } \\
\text { equipment }\end{array}$ & Weights & Ranking \\
\hline $\begin{array}{l}\text { Fire engine } \\
\text { body and } \\
\text { security }\end{array}$ & 1 & 2.734 & 2.662 & 3.307 & 0.455 & 1 \\
\hline $\begin{array}{l}\text { Accessory } \\
\text { rescue } \\
\text { equipment }\end{array}$ & 0.366 & 1 & 2.768 & 2.654 & 0.269 & 2 \\
\hline $\begin{array}{l}\text { Supplier } \\
\text { conditions }\end{array}$ & 0.376 & 0.361 & 1 & 3.200 & 0.182 & 3 \\
\hline $\begin{array}{l}\text { Built-in } \\
\text { equipment }\end{array}$ & 0.302 & 0.377 & 0.312 & 1 & 0.094 & 4 \\
\hline Subtotal & 2.044 & 4.472 & 6.743 & 10.162 & 1 & \\
\hline 2max = 4.264, C.I. $=0.088$, C.R. $=0.098$ in line with the requirements of consistency \\
\hline
\end{tabular}


According to the above, among the factors influencing the purchase of a fire engine and principal criteria, Miaoli County Fire Bureau attached the greatest importance to the body and security of a vehicle with a percentage of importance of nearly $50 \%$. Besides, due to the needs and characteristics of tasks, accessory rescue equipment is a significant factor influencing the purchase, followed by supplier conditions and built-in equipment. Many researchers in Taiwan studied the factors influencing the purchase or repurchase of a vehicle by a consumer. Chi (2006), Shih (2010), Chen (2005), and Chien (2014) assumed that vehicle safety and relevant functions were important influencing factors, which was in line with the result of this study that the firefighters of Miaoli County Fire Bureau and procurement experts believed that "vehicle body and security" was important.

\subsection{Analysis on the Importance of the Factors Influencing the Purchase of a Fire Engine and Secondary Criteria}

The secondary criteria of this study were classified into four main categories with a total of 18 items, including: "engine power (horsepower/torque)," "brake", "chassis (controllability)," "rigid structure of the body", "electronic safety equipment", "PTO", "accessory rescue equipment", "equipment spatial planning", "equipment difficulty of operation", "equipment availability", "brand", "service quality", "vehicle quality", "maintenance", "performance", "GPS", "driving recorder", and "double cabs of the front compartment". Through the analysis of the factors with AHP, the order of selection is shown in Table 4:

1. Vehicle body and safety: brake $>$ engine power (horsepower/torque) $>$ chassis (controllability) $>$ electronic safety equipment. The scores of brake and engine power were close. Since the total weight of a fire engine is much greater than an average vehicle, the requirements of brake which influencing safety and engine power were higher. Thus, they were the most important factors among the secondary criteria.

2. Accessory rescue equipment: PTO $>$ accessory rescue equipment $>$ equipment difficulty of operation $>$ equipment spatial planning $>$ equipment availability $>$ maintenance. PTO affects the devices related to engine. If PTO is invalid, firefighters and other people on spot will face great risks. PTO is a unique factor in the purchase of a fire engine which is different from that of an average vehicle.

3. Supplier conditions: Service quality $>$ maintenance $>$ vehicle quality $>$ performance $>$ brand. Service quality, maintenance, and vehicle quality were ranked as the top three factors in terms of supplier conditions. Their weights were close. It shows that the factors related to service and quality are emphasized by firefighters and fire fighting experts with practical experiences in terms of the purchase of a fire engine.

4. Built-in equipment: GPS $>$ driving recorder $>$ double cabs of the front compartment. GPS and driving recorder were ranked as the top two factors in terms of built-in equipment with close weights. It shows that firefighters and procurement experts focus on the factors influencing the completion of a task rather than driving comfort emphasized by an average driver. 
Hung-Teng Chang et al.

Table4. Analysis on the Importance of the Factors Influencing the Purchase of a Fire Engine by Miaoli County Fire Bureau

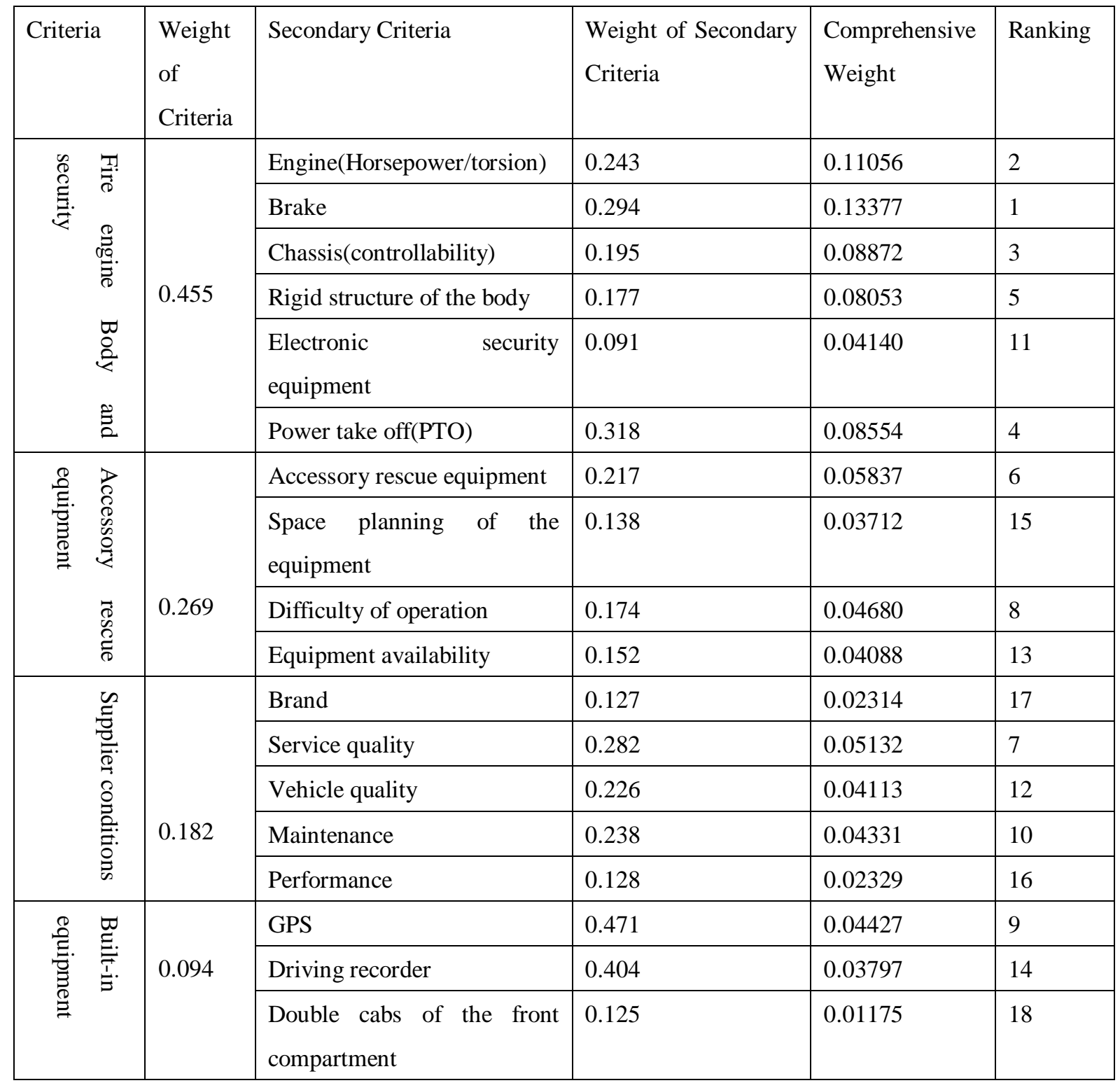

\subsection{Analysis on the Importance of the Factors Influencing the Purchase of a Fire Engine}

Table 3 and Table 4 show that in terms of the purchase of a fire engine, firefighters and procurement experts attach the greatest importance to vehicle body and security highlighted with a score of 0.455 in the item of "vehicle body and security" in principal criteria. In the discussion of the single factor of "vehicle body and security", "brake" receives the most attention. In the analysis of accessory rescue equipment, "PTO" receives the most attention. In the analysis of supplier conditions, "service quality" receives the most attention. In the analysis of built-in equipment, "GPS" receives the most attention.

Overall speaking, the evaluation of the 18 secondary criteria shows that the top six factors by weight are brake (0.13377), engine power (0.11056), chassis (controllability) (0.08872), PTO (0.08554), rigid body structure (0.08053), and accessory rescue equipment $(0.05837)$. All the six criteria account for $56 \%$ of the total weight, so they receive [high attention] from firefighters and 
Discussion on the Specifications and Needs of Fire Engines Procured by Miaoli County Fire Bureau

procurement experts. The criteria ranked from the seventh to the twelfth are service quality (0.05132), equipment difficulty of operation (0.04680), GPS (0.0564), maintenance (0.04331) electronics safety equipment (0.04140), and vehicle quality (0.04113). All the six criteria account for $27 \%$ of the total weight, so they receive [moderate attention] from firefighters and procurement experts. The rest receive [low attention] from firefighters and procurement experts.

Table5. Analysis on the Importance of the Criteria Influencing the Purchase of a Fire Engine by Miaoli County Fire Bureau

\begin{tabular}{|c|c|c|c|c|}
\hline $\begin{array}{l}\text { Weights } \\
\text { Ranking }\end{array}$ & $\begin{array}{l}\text { Comprehensive } \\
\text { Weight } \\
\text { Distribution }\end{array}$ & Criteria Evaluation & Aspects & $\begin{array}{l}\text { Degree of } \\
\text { Importance } \\
(\%)\end{array}$ \\
\hline 1 & 0.13377 & Brake & $\begin{array}{l}\text { Fire engine body and } \\
\text { security }\end{array}$ & $56 \%$ \\
\hline 2 & 0.11056 & Engine(horsepower/torsion) & $\begin{array}{l}\text { Fire engine body and } \\
\text { security }\end{array}$ & \\
\hline 3 & 0.08872 & Chassis(controllability) & $\begin{array}{l}\text { Fire engine body and } \\
\text { security }\end{array}$ & \\
\hline 4 & 0.08554 & Power take off(PTO) & $\begin{array}{l}\text { accessory rescue } \\
\text { equipment }\end{array}$ & \\
\hline 5 & 0.08053 & Rigid structure of the body & $\begin{array}{l}\text { Fire engine body and } \\
\text { security }\end{array}$ & \\
\hline 6 & 0.05837 & Accessory rescue equipment & $\begin{array}{l}\text { accessory rescue } \\
\text { equipment }\end{array}$ & \\
\hline 7 & 0.05132 & Service quality & Supplier conditions & $27 \%$ \\
\hline 8 & 0.04680 & Difficulty of operation & $\begin{array}{l}\text { accessory rescue } \\
\text { equipment }\end{array}$ & \\
\hline 9 & 0.04427 & GPS & Built-in equipment & \\
\hline 10 & 0.04331 & Maintenance & Supplier conditions & \\
\hline 11 & 0.04140 & Electronic security equipment & $\begin{array}{l}\text { Fire engine body and } \\
\text { security }\end{array}$ & \\
\hline 12 & 0.04113 & Vehicle quality & Supplier conditions & \\
\hline 13 & 0.04088 & Equipment availability & $\begin{array}{l}\text { accessory rescue } \\
\text { equipment }\end{array}$ & $17 \%$ \\
\hline 14 & 0.03797 & Driving recorder & Built-in equipment & \\
\hline 15 & 0.03122 & $\begin{array}{l}\text { Space planning of the } \\
\text { equipment }\end{array}$ & $\begin{array}{l}\text { accessory rescue } \\
\text { equipment }\end{array}$ & \\
\hline 16 & 0.02329 & Performance & Supplier conditions & \\
\hline 17 & 0.02311 & Brand & Supplier conditions & \\
\hline 18 & 0.01175 & $\begin{array}{l}\text { Double cabs of the front } \\
\text { compartment }\end{array}$ & Built-in equipment & \\
\hline
\end{tabular}


The results show that "vehicle body and security" is extremely important. In the secondary criteria ranked top six, it accounts 4 items. It shows that brake, engine power (horsepower/torque), chassis (controllability), and rigid body structure are important specifications in terms of the procurement of a fire engine for fire fighters and procurement experts. Thus, factors related to safety have influence, prediction, consistency, and continuity for fire fighters and procurement experts in terms of the purchase of a fire engine, directly affect purchase decision model, and are the most important factors influencing to the purchase.

\section{CONCluSion}

This study treated the fire fighters and procurement experts in Miaoli County as its subjects, analyzed the factors influencing the purchase of a fire engine based on literature review, brainstorming, Modified Delphi Method questionnaire of experts, conducted the questionnaire with AHP, collected, analyzed, and discussed data, and understood the status quo of the purchase and needs of a fire engine of the fire fighters and procurement experts in Miaoli. Please refer to the below conclusion and relevant suggestions:

1. The proportions of the factors receiving high, moderate, and low attention from the firefighters and procurement experts are $56 \%, 27 \%$, and $17 \%$, respectively.

2. The order of the six influencing factors influencing the purchase of a fire engine and receiving high attention is: Brake, engine power (horsepower/torque), chassis (controllability), PTO, rigid body structure, and accessory rescue equipment, most of which belong to the aspect of vehicle body and security. The order of the influencing factors influencing the purchase of a fire engine and receiving moderate attention is: Service quality, difficulty of operation, GPS, maintenance, electronic safety equipment, and vehicle quality. The order of the influencing factors influencing the purchase of a fire engine and receiving low attention is: Equipment availability (quality), driving recorder, equipment spatial planning, performance, brand, and double cabs of the front compartment.

3. The main factors affecting the purchase of a fire engine: Brake accounts the highest weight. Its content evaluated includes reaction, average force, drainage, structure, braking force, and frequency of replacement. The content of engine power evaluated includes fuel, ignition, cooling, lubrication, and engine power. The content of chassis (controllability) evaluated includes installation location, drive wheel configuration, driver's vision, vibration, stability of direction, steering angle, vision, noise, and cooling effect. The content of PTO evaluated includes power take off. The content of rigid body structure evaluated includes safety, fuel consumption, comfort, vehicle center of gravity, and productivity. The content of accessory rescue equipment evaluated includes the compliance with the objectives and characteristics of tasks. 


\section{REFERENCES}

Channel-Auto (2015). Core of the Safty of a Vehcile-Vehicle Body, CRI Online. Retrieved on: December 10, 2015, www.crionline.cn.

Chen, S. Y. (2005). The Effect of Loyalty Programs, Perceived Value, Post-Purchased Satisfaction, Anticipated Regret and Loyalty Intention-The Case of Automobile Industry. Master's thesis, Institute of International Business, National Cheng Kung University, Tainan City.

Cheng, T. C. \& Lin, W. H. (2004). Study on the Establishment and Application of Functional and Technical Specificationof Digital Driving Recorde. CECI Engineering Technology, 63. Retrieved on: December 10, 2015, http://www.ceci.org.tw/book/63/ch63hp.htm.

Chi, W. (2006). A Study on Durable Replacement Decision Model-An Automobile Case. Master's thesis, Graduate School, Department of Business Administration, Soochow University: Taipei City.

Chien, C. F. (2014). The Determinants of the Customers for Purchasing Taiwan OBM Vehicles A Case Study of Luxgen Motors. National Cheng Kung University (EMBA), Hsinchu City.

Feng, T. Y. \& Chen, Y. H. (2015). Marketing in a Social Media Environment: The Impact of Interactivity and Argument Quality on Consumer Purchase Intentions. Information Transmission Research, 5 (2), 47-71.

Hsiao, F. F. (2012). Consumer Behavior. Taipei City: Best-Wise Publishing.

Huang, T. C. (2009). Operation of Vehicle Equipment and Device. New Taipei City: Fire Department, New Taipei City Government.

Kao, J.C., Ko, L.M., and Su, H.B. (2015). Consumers Behavior at Swimming Pools in Taichung-A Case Study of Top Swimming School. Xingda PE Journal, 14, 37-49.

Lai, H. J., Tung, T. C., and Huang, K. L. (2011). Sedan Form and Visual Angle to Consumers of Attraction Influence. Journal of Cultural and Creative Industries Research, 1(1), P 39-48.

Lee, W. H. (2003). Generation Automobile Consumers' Purchasing Behavior. Master's thesis, ENBA, Chiao Tung University, Hsinchu.

Ministry of Education (2015). Revised Mandarin Chinese Dictionary. Retrieved on: December 10, 2015, http://dict.revised.moe.edu.tw.

National Fire Agency (2004). Code of Practice of the Management and Maintenance of Device and Equipment of a Fier Engine, Fire Control Law. Taipei City: Ministry of the Interior.

National Fire Agency (2011). Fire Control Law. Taipei City: National Fire Agency.

National Fire Agency (2015). Case Study. Taipei City: Department of Civil Service Ethics, Ministry of the Interior.

Phoenix Chen (2001). A Study of Procurement Tendering Procedures of Public-owned Enterprises -A Case Study Approach. Master's thesis, Department of Finance, National Sun Yat-sen University: Kaohsiung City. 
Shi, C. H. (2010). Diesel Car Purchasing Behavior Intention Analysis. Department of Transportation and Logistics Management, Hsinchu City.

Tsai, C. J. (2007). Vehicle Body Structure-Vital to Safety. AutoNet, Retrieved on: December 10, 2015, http://www.autonet.com.tw.

Tseng, S. P. and Hsieh, M. Y. (2012). Discussion on the Corelation of Brand Image with the Purchase Intention of the Middle-aged and the Senior. Jiada PE Health and Leisure Journal, 11(1), 265-271.

Tu, S. L., Lin, C. L., Chen, Y. H., and Huang, W. T. (2010). Special Report on "Welfare Benefits Business and Purchase and Analysis of the Equipment of Fire Rescue System”. Taipei City, Supreme Prosecutor Office.

Wang, H. M. (2001). Training on the Platemetal of a Vehicle-Understanding the Structure of a Vehicle. Taipei City: Vocational Training and R\&D Center of the Republic of China.

www.nani.com (2015). GPS. Retrieved on: December 10, 2015, www.nani.com.tw/nani/jlearn/ soci/extra /a/a2_7.htm. 